\title{
Impact of COVID-19 on Indian Sugar Industry
}

\author{
S. Solomon ${ }^{1,2} \cdot$ Govind Pratap Rao ${ }^{3}$ M. Swapna ${ }^{1}$
}

Received: 10 May 2020/Accepted: 16 May 2020/Published online: 29 May 2020

(C) Society for Sugar Research \& Promotion 2020

\begin{abstract}
The Indian sugar industry, a significant player in the national economy, has faced many challenges in the course of its journey. The threat posed by the growing pandemic novel corona virus (COVID-19), has been the most recent one and it is impacting sugar industry stakeholders and its integrated industries, not only in India, but all over the world. The entire value chain of the Indian sugar industry, viz., sugarcane, sugar, molasses, ethanol and their subsequent marketing and export, has been adversely affected from the spillover impacts. The major impacts of COVID-19 on Indian sugar industry are discussed.
\end{abstract}

Keywords Sugar industry - Impact of corona . Sugar consumption $\cdot$ Sugar price $\cdot$ Sugar export . Diversification · Unemployment

The Indian sugar industry plays a leading role in the global sugar market, being the world's second largest sugar producer after Brazil, producing nearly 15 and $25 \%$ of global

\author{
M. Swapna \\ sugarswapna@gmail.com \\ S. Solomon \\ drsolomonsushil27@gmail.com \\ Govind Pratap Rao \\ gprao_gor@rediffmail.com
}

1 ICAR-Indian Institute of Sugarcane Research, Lucknow, Uttar Pradesh 226002, India

2 CSA University of Agriculture and Technology, Kanpur, Uttar Pradesh 208003, India

3 Division of Plant Pathology, Indian Agricultural Research Institute, Pusa Campus, New Delhi 110012, India sugar and sugarcane, respectively. It is a significant contributor to the socio-economic development of the nation. The sugar industry encompasses 597 operating sugar mills, 309 distilleries and 213 cogeneration plants and numerous pulp, paper and chemical making units. The area under sugarcane hovers around 5 million ha which is nearly $3 \%$ of the gross cultivable area in the country. The industry produces around 350-400 MT cane, 25-30 MT white sugar and 6-8 MT jaggery and khandsari to meet the domestic requirement of sweeteners. Besides, about 2.9 billion litres of alcohol is also being produced annually and the industry is fully capable of meeting demand of potable alcohol as well as $10 \%$ blending in gasoline. The sugar mills are gradually transforming into sugar complexes by producing sugar, bio-electricity, bio-ethanol, bio-manure and chemicals; these contribute about $1.1 \%$ to the national GDP. Currently, the annual turnover of the sugarcane and sugarrelated economic activities is in the range of USD 16-17 billion (Solomon, 2014). In view of the extended lockdown due to COVID-19 pandemic, the entire value chain of sugar industry linked to sugarcane, i.e. sugar, ethanol and other economically important products and by-products, especially their production, consumption, transport and export, is likely to be disrupted. According to the Indian Sugar Mills Association (ISMA), nearly INR 70,000 crore has been stuck in unsold sugar and ethanol inventories in sugar mills, the demand for ethanol has also fallen due to the drastic dip in fuel consumption. These elements have dented the cash flow of sugar mills and impaired their ability to pay cane farmers. Even if the lockdown is lifted by the end of May 2020, the industry would fail to make up for the lost opportunity. The possible impacts of COVID19 and pragmatic steps taken by the government and industry during these tough times are discussed herein. 
During the initial days of lockdown, due to the shortage of labour and critical inputs like lime, sulphur, packaging material and other related challenges, there has indeed been a reduction in sugar production in the country. Sugarcane and sugar are predominant parts of the Essential Commodity Act 1955, and therefore sugar mills across India which have not completed their sugarcane crushing operations will continue to operate. The Ministry of Home Affairs has issued necessary guidelines on the measures to be taken for containment of COVID-19 pandemic in the country which mentioned that industrial establishments would remain closed; however, manufacturing of essential commodities and their transportation will be exempted. The government has ensured free inter-state and intra-state movement of trucks carrying the essential materials for sugar industry. The Ministry of Consumer Affairs, Food and Public Distribution has also taken necessary steps to ensure availability of key inputs for sugar manufacturing plants, including sulphur, lime, phosphoric acid and packaging bags for uninterrupted working of sugar mills. This has facilitated the smooth functioning of the sugar mills during the later part of the lockdown. As on 15th April 2020, 24.8 million tons of sugar have been produced by the sugar mills in the country, which is a reduction of approximately $20 \%$ (6.4 million tons) when compared to that in the previous year. Since the crushing operations in 90 sugar mills are still continuing due to availability of cane, sugar production to the tune of 27 MT could be expected in this sugar season. According to ISMA, sugar mills across the country have produced 25.80MT of sugar between 1st October 2019 and 30th April 2020. This is about 6.37 MT less than $32.17 \mathrm{MT}$ of sugar produced in the same period last year. India is expected to produce 26.85MT sugar in 2019-2020 season as against 33.16 MT tonne produced in the previous year.

The recent corona crisis (COVID-19) is adversely affecting the present and future activities of sugar industry by interfering with the national and international sugar and ethanol business. It will have an effect, directly or indirectly, on sugar industry stakeholders and its integrated industries. A significant impact due to the COVID-19 lockdown would be on the sugar consumption. It is estimated that there will be a drastic decline in demand for sugar from the bulk consumers as the commodities like ice cream/cold drinks/confectionery are produced less during this period. Sugar supplies to the aerated and non-aerated beverages manufacturers is greatly reduced as they have suspended operations in bottling plants during the summer time when demand for such beverages is high. The hotel, retail and catering market segment, which is one of the largest consumers of sugar, is among the industry's most severely impacted by the national lockdown as all hotels, restaurants, bars, sweetmeat shops and other miscellaneous food establishments have been closed. The institutional consumption of sugar in India is estimated to be around $65 \%$ of total domestic sugar sales. The corona pandemic could impact the overall domestic sugar consumption by 1.0-1.5 MT. With a fall in the demand, the sugar mills have failed to fulfil their monthly sales quota of sugar, thereby leading to a reduced income. This in turn has led to less realization of working capital, and the mills are unable to pay the cane arrears to farmers. Sugar mills are struggling hard to pay the cane arrears of about INR 16,000 crore, as sales have been reduced to $50 \%$ and global prices have drastically fallen down. Recently, the Government has taken a favourable step of extending the period for selling the sugar sale quota of March 2020. This has certainly given a relief to sugar millers across the country to sell their sugar stocks.

This reduced consumption and demand has led to a significant drop in sugar prices globally. Thus, sugar export may not become an attractive strategy for many countries including India. In India, this will lead to an increase in the carryover of sugar stocks by 10-12 million tons. The top export destinations for Indian sugar are Iran, Somalia, Malaysia, Bangladesh and Sri Lanka. The COVID-19 crisis has resulted in a slowdown of port operations owing to low container traffic, limited labour availability, absence of courier services and public transport and with minimum customs operation during the crisis. According to All India Sugar Trade Association, of the 3.75 million tonnes of sugar export deals agreed since the start of the season on October 1, 2019, Indian mills have so far shipped out 2.86 million tons. The sugar mills have dispatched nearly 3.0 million tonnes of sugar from their stocks in this season that started in October 2019, as against MAEQ (Maximum Admissible Export Quantity) target of 6.0 million tonnes. India's sugar sales in both domestic and overseas markets have taken a beating in view of the nationwide lockdown for preventing the spread of the deadly COVID-19.

But all is not lost for India in the export scenario. Even though exports might not be very attractive at a global level, Indonesian sugar markets are a safe option, especially with Thailand, a major sugar exporter to Indonesia recording a reduction in sugar production to the tune of 6.5 MT, which is expected to decline further during the next year. The recent decision of Indonesian Government to allow 600 ICUMSA sugar at a concessional import duty from India, Australia and Thailand, gives an additional opportunity for India to export large quantities of sugar to Indonesia. In addition, Indonesian Government has issued an additional import quota to its refineries. Indian sugar industry can take advantage of this situation, and this country can be a major export market for India. ISMA and the sugar mills are now pinning hopes on prospective shipments to Indonesia to make up for the accumulating losses. 
Another significant area that will be impacted is the diversion of cane for ethanol production and related byproducts. A decline in crude oil prices has made diversion of cane to ethanol production uneconomical. The price of crude oil tumbled down to US\$32/barrel in March 2020; this may further reduce to US\$20/barrel exacerbated by the COVID19 pandemic. The consequence of this is that millers in Brazil may divert more cane to sugar production than to ethanol, which is becoming less competitive with gasoline. In Brazil, only $52 \%$ (as against the usual $67 \%$ ) of the canes is going to be diverted for ethanol production, and thus, we can anticipate an increase in sugar production by 6-7 million tons. This is likely to result in a glut in the global sugar markets with an expected fall in global sugar prices from USD 425/ton of sugar to around USD 300/ton of sugar. This will again be unfavourable for export of sugar to global markets. Fresh sugar procurement from mills would start soon since the supply chain would have largely dried up during the last couple of weeks, which should control sugar prices while the fresh buying should help the domestic mills.

As far as ethanol production in India is concerned, the initial reduction in the off-take of ethanol by OMCs had led to an initial setback, but reallocation to different locations has led to a regularized off-take. So ethanol has now started going to newer depots in Jharkhand, Bengal, Madhya Pradesh, Chhattisgarh, Rajasthan, Gujarat, Andhra Pradesh, Telangana and Kerala. Efforts are being explored to see whether ethanol can be sent to Odisha and Assam too. Moreover, many of the sugar mills have started the production of alcohol-based hand sanitizers. With the rising demand of hand sanitizers owing to the COVID-19 pandemic and inclusion of "Hand Sanitizers" as an essential commodity under the Essential Commodities Act, up to 30th June, 2020. Sugar millers across the country are playing a significant role in fulfiling the requirement of alcohol-based sanitizers. According to Indian Sugar Mills Association, the domestic sugar industry could supply adequate quantities of ethanol or extra neutral alcohol (ENA) according to the requirement for use in the manufacture of hand sanitizers. Nearly 50 sugar mills pan India have created sanitizer capacities totalling 100,000 litres per day. This new segment of production of hand sanitizers has been successfully launched very quickly by most of the sugar companies, Those who have already forayed into the segment include firms such as Balrampur Chini Mills Ltd., Uttar Pradesh, Bajaj Hindusthan Sugar Ltd., Dhampur Sugar Mills Ltd. and sugar mills under Triveni Group, Dalmia Sugars etc.

A few states like Maharashtra and Karnataka have reported that the ongoing sugarcane harvesting and transport has been seriously affected by the gradual spread of COVID19. The nationwide lockdown has hit the sugar industry adversely in Maharashtra with an inordinate delay in the harvesting of almost 1.0 million tons of sugarcane, leading to a possible reduction in sugar production from the state by more than one lakh metric tonnes. In Karnataka, between October 2019 and March 2020, factories crushed 3.38MT of sugarcane, which is a decline of $15 \%$ over that during the corresponding period in the previous year. However, in Uttar Pradesh, it is estimated that more than $90 \%$ of the cane crushing has been completed. As per a recent report, Uttar Pradesh has produced 12.42 MT sugar as on May 23, 2020, which is 6.82 lakh tonne higher than previous year. In view of the lockdown, factories have been advised not to allow labourers to leave their locations and to make the necessary arrangements for food and shelter. The Government has recently issued necessary directives that the entire value chain viz., cane, sugar, ethanol, other by-products etc. has been put under the essential commodities act (ECA) for seamless operations. This is essential in view of the spring and summer plantings which are underway in North Indian states. The lockdown and the related challenges may adversely affect the sugarcane planting and field maintenance activities to a certain extent. Even though there is a prediction for an overall normal monsoon, a below-normal rainfall during June and an extended dry spell in July that are being foreseen might add to the difficulties faced during the initial stages of the crop. Thus, there is a possibility that the sugarcane production will face a marginal decline during 2020-2021, but the overall predictions suggest that the cane production will be more than that in the current year. The Indian Council of Agricultural Research (ICAR) has also issued advisory for harvesting and threshing of Rabi crops and post-harvest, storage and marketing of farm produce in the wake of COVID-19 threat, including sugarcane. This should also aid the stakeholders to overcome the adverse situations, to a great extent.

Another related sector that has been severely affected by COVID-19 is the jaggery manufacturing. The shortage of labour has severely affected the working of the jaggery units across the country. But in case there is an assured supply of labourers, the jaggery sector can take advantage of the situation and any cane left unharvested can be diverted for jaggery production. Especially in areas where the mills have closed due to shortage of labourers for cane harvesting, the standing canes can be used for jaggery production utilizing the household labour available.

The data from the Centre for Monitoring Indian Economy (CMIE) showed that India's unemployment rate surged to $24.6 \%$ as on 07 th May 2020 due to suspended economic activity to counter the spread of COVID-19. In view of continuing restrictions on movement of people and vehicular traffic, concerns have been raised regarding negative implications of COVID-19 pandemic on the sugar sector where $7.5 \%$ of total rural population is directly engaged and nearly 0.5 million rural people are employed. The farm activities are likely to be hampered by shortage 
of farm labourers in some states. According to International Labour Organization, COVID-19 may leave a devastating impact on the global economy, sending urban and suburban unemployment rate soaring to over 30\% (Anonymous 2020). In order to mitigate the crisis, Indian Finance Minister declared an INR 1.7 trillion package, mostly to protect the vulnerable sections (including farmers) from any adverse impacts of the Corona pandemic. Besides, advance release of INR 2000 to bank accounts of farmers as income support under PM-KISAN scheme was also announced. Cash and food assistance to persons engaged in the informal sector, mostly migrant labourers, have also been announced for which a separate PM-CARES (Prime Minister Citizen Assistance and Relief in Emergency Situations) fund has been created.

\section{Way Forward for the Indian Sugar Industry}

- Sugarcane is a long duration labour-intensive crop, and therefore planting and field operations can be affected by long periods of/frequent lockdowns. There need to be an enhanced emphasis on mechanization efforts for different cultural practices like planting, inter-cultural operations, ratoon management and harvesting.

- Custom-hiring facilities and cost-effective farm machinery suited to small and marginal farmers should be given utmost priority.

- The sugar sector should explore potential applications of Artificial Intelligence (AI) in sugarcane production management, crop and soil health monitoring, predictive crop-analysis and in creating smart supply chain.

- The Indian sugar industry should intensify its effort for diversification/specialty products and value addition. Research on developing specialty sugars, low GI sugars, neutraceuticals, wellness products, pharmaceuticals etc., from sugarcane co-products and sugars should be given emphasis.

- Alternate use of by-products like bagasse (chemicals, resins), filter cake (e.g. bio-methane, bio-CNG) etc., should be exploited at commercial level.

- Since the air-quality has been found to improve during the lockdown period as per various reports, this airquality needs to be maintained and ethanol blending can be an excellent strategy to meet this goal. Thus, more sugarcane molasses/juice can be processed towards ethanol production and if possible, blending of $10 \%$ and more should be achieved at the earliest. Around 5.11 BL of ethanol was estimated to be required in 2019-2020, however, current installed capacity in sugar mills from all sources is only 3.55 BL. There is tremendous scope for our sugar factories to enhance the production of ethanol using all possible resources including cane juice, B-Heavy molasses etc.

- COVID-19 has emphasized the need for ensuring hygienic surroundings, and the production of hand sanitizers can be a continuing process. This also will result in an enhanced demand for RS and ENA in imminent future

- The industry should lay more emphasize on globalization of manufacturing and other services/products with a proper utilization of the upcoming opportunities.

- India's alcohol industry is the third largest in the world, revenue in the spirits segment amounts to US\$36,944 m in 2020. The market is expected to grow annually by $6.6 \%$ (CAGR 2020-2023). India faces IMFL deficit of around 1000 million litres with room for more. In case GOI makes $10 \%$ ethanol blending with petrol mandatory, another 1380 million litres deficit would arise. The sugar sector therefore has great opportunity to boost IMFL production by expanding the capacity of its distilleries and advanced technologies to produce ethanol from multiple raw material such as biomass/sugar beet/left over grains/potato/starch-based products etc.

- To reduce the debt and pare rising inventories, the government has approved a subsidy of INR 10,448 (\$137.5) a tonne for exports of 6 million tonnes in the 2019-2020 season ending on September 30. More such initiatives should be there from the Government of India. The sugar mills in Karnataka have demanded a rescue package of INR 1000 crore from Karnataka Government, in the form of soft loans, Government guarantee to make cane payment, carry out maintenance of the mills etc. The South Indian Sugar Mills Association (SISMA) has also requested the governments to supply fertilizers, pesticides etc., free of cost to the sugarcane growers and also extra credit facilities. In essence, all subsidies and soft loans admissible to sugar industry should be allocated to the food ministry in a budgetary package and be released against the claims of mills. Agricultural term and crop loans should be granted a moratorium of 6-9 months by banking institutions.

- Agri-business, entrepreneurship and export opportunities in diversified open pan products, organic sugar, organic chewing cane and juice.

The industry is at cross roads today due to the ongoing COVID-19 crisis, and therefore micro-level planning for identifying the current and future developmental need of the sugar sector is essential. This is imperative so that with the limited resources and adverse climatic conditions, farm and factory productivity could be sustained and stakeholders across the value chain-farmers, millers, retailers and international traders enjoy better prosperity. Many of these impacts may be temporary and the industry might soon find 
itself bouncing back as in many of the previous occasions. But strategies like increased mechanization in the grower's fields, diversification and ethanol blending, value addition, etc., are here to stay and strengthen, to enable the industry overcome such unforeseen adversities and challenges towards a better sustainability.

\section{References}

Anonymous. 2020. International Labor Organization. Almost 25 million jobs could be lost worldwide as a result of COVID-19, says ILO. March 18, 2020.

https://www.ilo.org/global/about-the-ilo/newsroom/news/WCMS_73 8742/lang-en/index.htm. Accessed May 4, 2020.

http://www.unemploymentinindia.cmie.com/. Accessed 7 May 2020. https://www.financialexpress.com. COVID-19 to put pressure on sugar industry as domestic consumption, exports to take a hit, FE Bureau, Published: April 16, 2020.

https://www.business-standard.com/. Covid impact: Domestic sugar consumption likely to dip 2 million tones Published: April 25, 2020.

https://www.financialexpress.com/. Lockdown impact: Domestic sugar consumption to fall by at least one million tonne says Icra PTI. Published: 27 April 2020.

https://www.deccanherald.com. Coronavirus lockdown: Sugar industry seeks Rs. 1000 crore bailout package from Karnataka govt. DHNS. Published: April 17, 2020.

Solomon, S. 2014. Sugarcane agriculture and sugar industry in India. Sugar Tech 16: 113-124.

Publisher's Note Springer Nature remains neutral with regard to jurisdictional claims in published maps and institutional affiliations. 